\title{
UTILIZAÇÃO DE FILMES COMO MATERIAL DIDÁTICO PARA ENSINO E APRENDIZAGEM DA EDUCAÇÃO AMBIENTAL: ESTUDO DE CASO
}

Eliana Débora Soares Teixeira ${ }^{1}$ Patrine Nunes Gomes ${ }^{2}$ Cecília de Souza Carvalho ${ }^{3}$ Marcília Martins da Silva ${ }^{4}$ Miria Cássia Oliveira Aragão ${ }^{5}$

Resumo: A Educação Ambiental é compreendida como uma abordagem importante no processo de conscientização e humanização diante da iminente crise ambiental. A pesquisa analisou a utilização de filmes como instrumento metodológico para a compreensão da Educação Ambiental no ensino fundamental maior com alunos de faixa etária de 11 a 13 anos de idade. 0 estudo foi realizado no município de Cristalândia do Piauí, na Unidade Escolar Padre Elizeu Cavalcante, onde foi aplicado um questionário um antes e após o filme, a fim de verificar a percepção dos alunos sobre a construção social da imagem de meio ambiente. Em se tratando dos problemas ambientais cerca de $82,75 \%$ responderam que são ocasionados por desmatamento, queimadas, poluição, exploração de madeira e acúmulo de lixo, cerca de 10,34\% responderam como sendo problema o lançamento de lixo nos corpos hídricos, no solo e nas ruas, e os $6,90 \%$ não souberam responder.

Palavras-chave: Educação Ambiental; Multimídia; Percepção.

\footnotetext{
1 Graduada em Tecnologia em Gestão Ambiental. Instituto Federal de Educação, Ciência e Tecnologia do Piauí, Correntes, PI. E-mail: elianasoares2050@gmail.com

${ }^{2}$ Graduada em Tecnologia em Gestão Ambiental. Instituto Federal de Educação, Ciência e Tecnologia do Piauí, Correntes, PI. E-mail: patrinenunes12@gmail.com ${ }^{3}$ Graduada em Tecnologia em Gestão Ambiental. Instituto Federal de Educação, Ciência e Tecnologia do Piauí, Correntes, PI. E-mail: cecycarvalho95@gmail.com

${ }^{4}$ Docente do Curso de Tecnologia em Gestão Ambiental. Instituto Federal de Educação, Ciência e Tecnologia do Piauí, Correntes, PI. E-mail: marcilia.martins@ifpi.edu.br

${ }^{5}$ Docente do Curso de Tecnologia em Gestão Ambiental. Instituto Federal de Educação, Ciência e Tecnologia do Piauí, Correntes, PI. E-mail: miria@ifpi.edu.br
} 


\section{Introdução}

A Educação Ambiental é uma abordagem importante para a conscientização e humanização das pessoas no que se refere a uma visão de proteção e cuidados ambientais, pensando nas futuras gerações (SANTOS 2016).

Não obstante, visa propor mudanças de atitudes e habilidades no intuito de promover a sustentabilidade dos recursos naturais, contribuindo para formar indivíduos com maior preocupação sobre a crise ambiental que ascende na sociedade contemporânea.

$\mathrm{Na}$ perspectiva apontada cabe a formulação de iniciativas capazes de aliar teoria e prática em espaços formais e não-formais no intuito de enfrentamento das diversas consequências de utilização predatória e desenfreada ao longo do tempo dos recursos naturais.

A Política Nacional de Educação Ambiental (PNEA), instituída pela Lei Federal no 9.795, de 27 de abril de 1999 define em seu art. 1ํㅡㄹcação Ambiental (EA) como:

Art. 1ํ Entende-se por Educação Ambiental os processos por meio dos quais o indivíduo e a coletividade constroem valores sociais, conhecimentos, habilidades, atitudes e competências voltadas para a conservação do meio ambiente, bem de uso comum do povo, essencial à sadia qualidade de vida e sua sustentabilidade (BRASIL, 1999).

Algumas pessoas na sociedade ainda dedicam pouca atenção aos problemas ambientais, contudo são inevitáveis as percepções sobre impactos ambientais sentidos em virtude de ações como desmatamento, contaminação dos corpos hídricos e do solo em decorrência do descarte inadequado dos resíduos sólidos e líquidos tóxicos, tornando-as impróprios para o uso, entre outros.

Com aumento populacional também aumentou consideravelmente 0 índice de produção e consumismo das sociedades. Tais considerações têm ocasionado diversos impactos na natureza, quais sejam: a geração dos resíduos, os quais geralmente por não passarem pelo processo de reciclagem acabam prejudicando a qualidade de vida dos indivíduos e gerando vários impactos negativos no solo e nos lençóis freáticos. (FERREIRA; PEREIRA; BORGES, 2013).

De acordo com Xavier e Nishijima (2010), a percepção ambiental é o conhecimento e a atitude que o ser humano tem sobre o meio ambiente em que cada pessoa possui a capacidade de observar e atuar diante dos diversos impacto sofridos pelo meio ambiente. De outro modo, para Sousa et al. (2017), a percepção do indivíduo e a Educação Ambiental estão intimamente relacionadas, de modo que, a Educação Ambiental proporcione que os Revbea, São Paulo, V. 14, № 4: 87-105, 2019. 
indivíduos participem significativamente na mudança da percepção ambiental quando estejam vinculadas as suas vivencias.

Deste modo, a inserção da EA nas escolas ganha grande notoriedade para o desenvolvimento das pessoas, pois poderá contribuir para a adoção de práticas que visem à conservação do meio ambiente, tais como dispor os resíduos em locais apropriados e assim não os dispor em terrenos baldios e em corpos hídricos, inserir áreas verdes nas cidades a fim de melhorar o clima e para o próprio lazer das pessoas e, além disso, fazer o plantio de árvores para compensar terrenos em que foram desmatados, ensinando-as desse modo a conservar os recursos naturais.

No ambiente escolar para que seja possível construir o conhecimento e sensibilizar as pessoas em relação à adoção dessas práticas sustentáveis, a EA é relevante, pois dispõe de vários métodos, orientando os professores, por meio da exposição de situações cotidianas.

Essas situações podem ser expostas na maneira de interferência da qualidade do meio ambiente, posteriormente mostrando as possíveis soluções que podem ser adotadas para que sejam evitados problema. E o uso de filmes como metodologia pedagógica pode auxiliar nesse processo abordando problemas ambientais de forma lúdica demonstrados em situações reais.

A inserção de recursos audiovisuais nas aulas é uma prática a qual proporciona melhor aprendizado para os alunos em que eles possuem maior facilidade de raciocínio e assimilar as reais situações que estão expostas na atualidade. Atualmente com o uso dos recursos tecnológicos audiovisuais nas escolas facilitou o processo de aprendizagem dos alunos, pois tal uso proporciona aos mesmos, melhor entendimento, além de torná-las mais dinâmicas, motivadoras e trazer sensações de prazer, mostrando ainda a realidade de maneira mais próxima, permitindo ainda uma melhor fixação de conhecimento, e até mesmo por ser algo inovador na educação escolar, que tem ganhado cada vez mais espaço nas escolas brasileiras (SANTOS 2016).

A utilização de mídias em sala de aula, como o uso de filmes são ações as quais proporcionam aos alunos métodos de melhor entenderem os ensinamentos, auxiliando os mesmos no processo de aprendizagem (PORTO, 2015). Portanto, a pesquisa se propôs a analisar a utilização do filme "Os Sem Floresta" como instrumento metodológico para o estudo da Educação Ambiental no ensino fundamental.

\section{Metodologia}

\section{Área de estudo}

O estudo foi realizado no município de Cristalândia do Piauí - PI, localizado no extremo sul do Estado do Piauí (" $10^{\circ} 39^{\prime} 11^{\prime}$ " S "e $45^{\circ} 11^{\prime}$ ' 06" W), estando a uma altitude de $469 \mathrm{~m}$ como mostra a Figura 1 (IBGE, 2019). O município compreende uma área de aproximadamente $1.203 \mathrm{~km}^{2}$, com população estimada em 8.29 4habitantes.

Revbea, São Paulo, V. 14, № 4: 87-105, 2019.

revista brasileira educação ambiental 


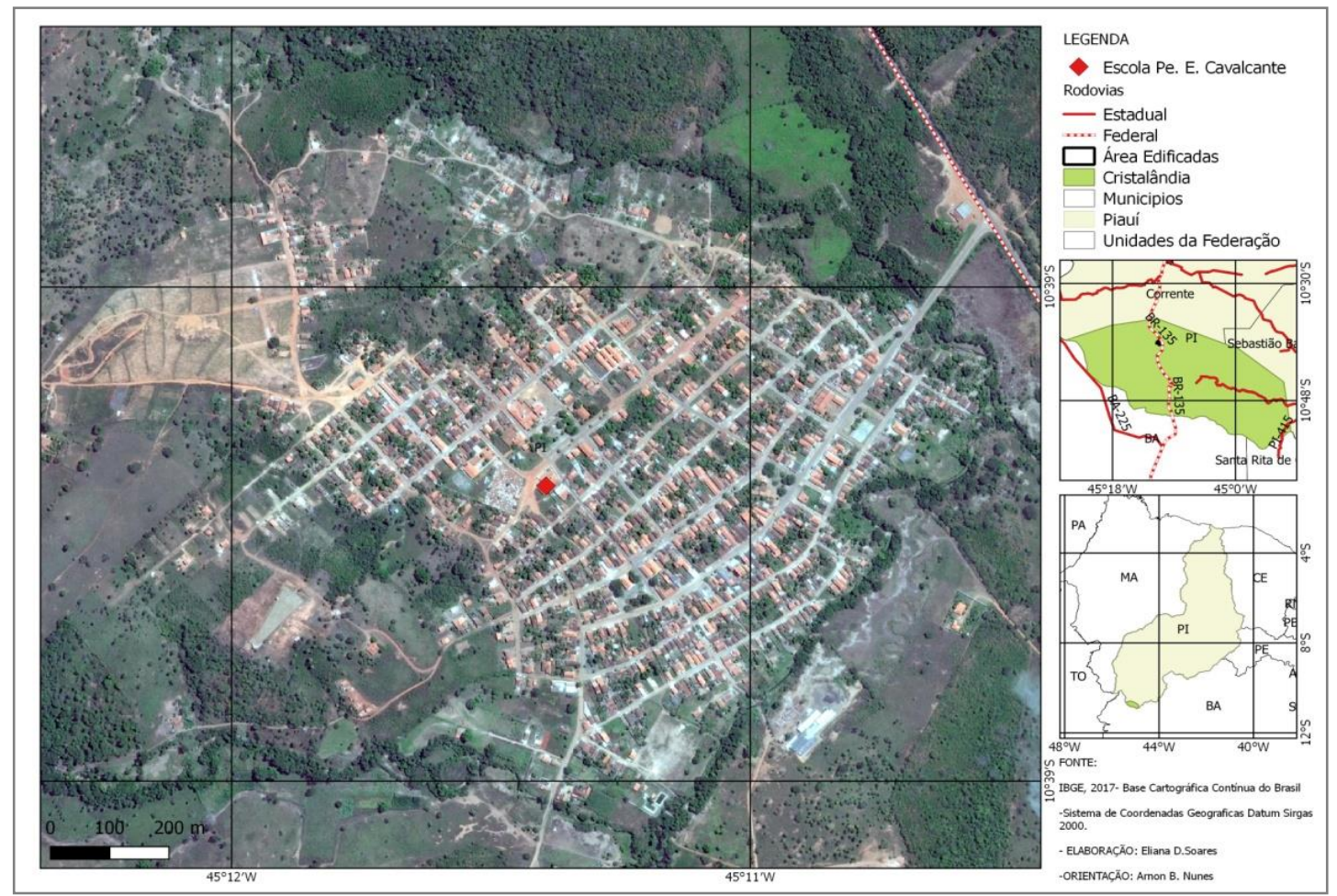

Figura 1: Localização do município de Cristalândia do Piauí - PI. Fonte: Autoras (2019).

A pesquisa foi realizada na Unidade Escolar Padre Elizeu Cavalcante que está localizada na zona urbana de Cristalândia, a escola contempla turmas do 5 ao 9ํao e possui em média 379 alunos.

\section{Procedimentos metodológicos}

Inicialmente foi realizado em revisão de literatura através de estudos em livros e trabalhos de conclusão de cursos, relacionados à temática. Em seguida, elaborou-se um questionário o qual foi utilizado como instrumento de pesquisa contendo 14 questões, sendo 11 abertas e 3 fechadas. Com o questionário buscou-se realizar uma caracterização socioeconômica e diagnosticar a percepção dos alunos referente ao tema meio ambiente. A aplicação do questionário aconteceu sem nenhuma intervenção para os 29 alunos da turma do 6o ano da Unidade Escolar Padre Elizeu Cavalcante, conforme mostra Figura 2 (próxima página_.

Foram escolhidos os alunos da série do 6을 ano da Unidade Escolar Padre Elizeu Cavalcante, devido os alunos estarem enquadrados na faixa etária adequada para assistir ao filme de animação, ou seja, estão em uma fase de elaboração e construção de conceitos sobre a realidade que os cercam e a animação aborda questões bastante atuais de maneira lúdica, podendo ser trabalhado de forma interdisciplinar e no cotidiano. 


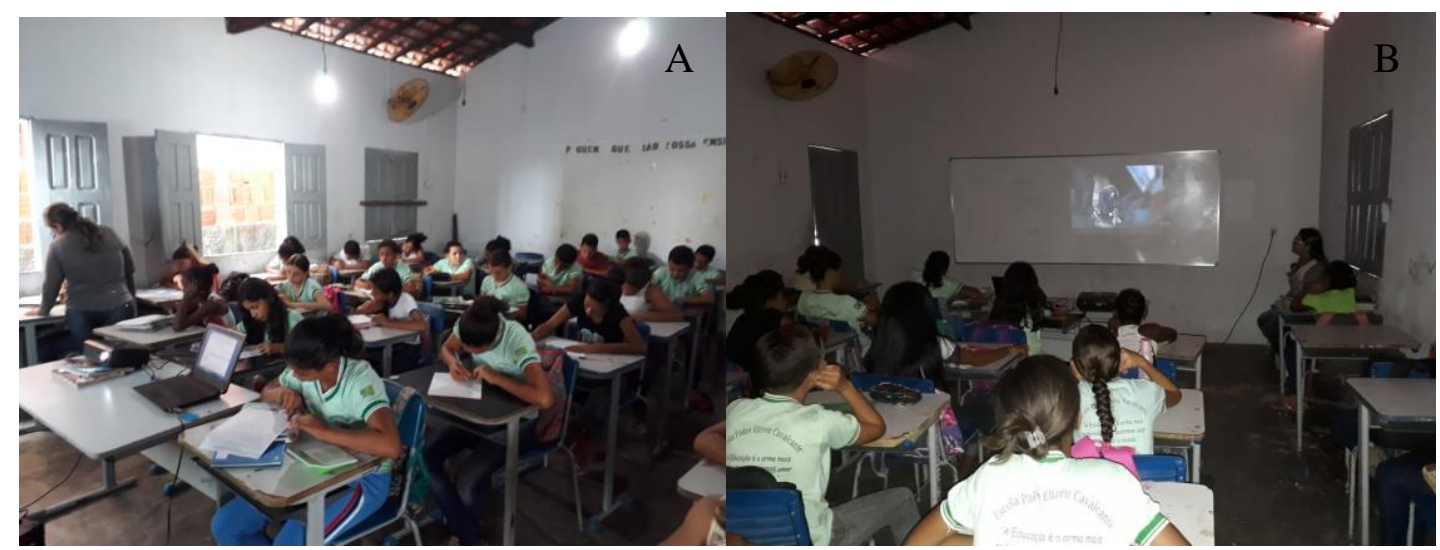

Figura 2: Aplicação do questionário antes do filme (A) e exibição do filme (B), respectivamente. Fonte: Autoras (2018).

A opção da escola se deu devido à logística facilitada, pois uma professora que trabalha na escola demonstrou interesse pela pesquisa e proporcionou oficialmente o contato com a direção da escola, facilitando assim a realização do trabalho.

Posteriormente foi exibido o filme "Os sem floresta", título original: Over the Hedge, filme e lançado $2006 \mathrm{com}$ 01h20min minutos de duração. Após à exibição do filme, o questionário foi reaplicado com intuito de avaliar se a percepção dos alunos mudaria após o filme, que abordava algumas problemáticas ambientais. A escolha deste filme foi feita devido ele mostrar alguns impactos ambientais causado pelo ser humano e por ser um filme voltado para público infantil.

Com título original "Over the Hedge", a obra cinematográfica "Os Sem Floresta" traz para o espectador a história de 12 animais silvestres que tentam encontrar novas formas de adaptação em seu habitat natural, cuja área foi consideravelmente diminuída em prol da construção de um condomínio habitacional, inserindo reflexões no que respeita à possível coexistência entre capitalismo e sustentabilidade em torno da reorganização da área florestal (ALMEIDA BIZARRIA, et al., 2017).

O filme aborda questões que tratam de fatos que ocorrem no meio ambiente como, a interferência antrópica devido à ocupação irregular das pessoas, gerando assim o consumismo, causando drásticas alterações no meio como a devastação das florestas, dizimação dos animais e plantas, extermínio dos animais, entre outros. 
As consequências do contato forçado entre humanos e animais que são reveladas no decorrer do filme também incitam discussões sobre a responsabilidade da sociedade e das organizações como protagonistas de políticas públicas ambientais, bem como da participação da educação na promoção de conhecimentos e valores favoráveis à preservação ambiental de forma individual e coletiva (ALMEIDA BIZARRIA, et al., 2017).

\section{Análise dos dados}

Foi realizada uma análise através da interpretação das perguntas respondidas no questionário e expostos em gráficos, bem como, foi realizada uma análise conceitual através da interpretação das imagens feitas sobre o meio ambiente. A segunda análise foi realizada diante da solicitação feita, como uma das questões do questionário, em que os alunos retratassem por meio de um desenho a sua percepção sobre o que é o meio ambiente. Esse processo ocorreu antes e depois da exibição do filme indicado. Além dos desenhos, abordou-se no questionário fatores sobre a percepção dos alunos no qual foram questionados (os problemas ambientais, os possíveis incômodos, responsáveis pelo surgimento e solução dos efeitos, relação de pobreza e riqueza com os problemas ambientais, práticas para conservar e percepção sobre resíduos).

\section{Resultados e discussão}

No filme "Os sem floresta" foram abordadas questões relacionadas aos problemas que a sociedade possui no cotidiano sendo eles: desmatamento que é mostrado no início do filme quando os animais acordam do período de hibernação e se deparam com boa parte da vegetação devastada e com muitas construções ao seu redor, os resíduos são mostrados quando os animais adentram as residências no intuito de buscar por alimentos e acabam carregando os mesmos para as ruas, na análise procurou-se verificar o que eles percebiam com relação a essa abordagem do filme.

E ainda a redução do habitat dos animais e consequentemente, o afugentamento deles isso devido às instalações feitas pelos humanos, a fim de capturar e afastar os animais que aparecem no condomínio em busca de alimentos. Com tudo isso, os animais acabam sendo expostos a riscos como, atropelamentos nas rodovias, pois saírem da natureza para se aventurarem nas cidades, em virtude da necessidade que esses possuem de procurar por alimentos. E esse contexto do filme foi o aporte para conexão com a realidade dos alunos escolhidos para a feitura dessa pesquisa.

Aliado a conceitos que permearam o transcurso teórico como a Lei $\mathrm{n}^{\circ}$ 6.938/81, que trata da Política Nacional do Meio Ambiente (PNMA), meio ambiente consiste em ser "o conjunto de condições, leis, influências e infraestrutura de ordem física, química e biológica, que permite, abriga e rege a Revbea, São Paulo, V. 14, № 4: 87-105, 2019. 
vida em todas as suas formas" (BRASIL, 1981). E a ISO 14001:2004, a qual define meio ambiente como: "circunvizinhança em que uma organização opera, incluindo-se ar, água, solo, recursos naturais, flora fauna, seres humanos e suas inter-relações" (ABNT, 2004).

\section{Caracterização socioeconômica}

Inicialmente, 0 trabalho buscou fazer uma caracterização socioeconômica dos alunos do $6^{0}$ ano da Unidade Escolar Padre Elizeu Cavalcante, constatando o identificativo que $51,72 \%$ possuem idade de 11 anos, 37,93\% apresentam 12 anos, 6,90\% com 13 anos e 3,45\% não respondeu, conforme mostra a Figura 3. Os dados demonstram que os alunos se enquadrarem na faixa etária adequada para a série que estão estudando.

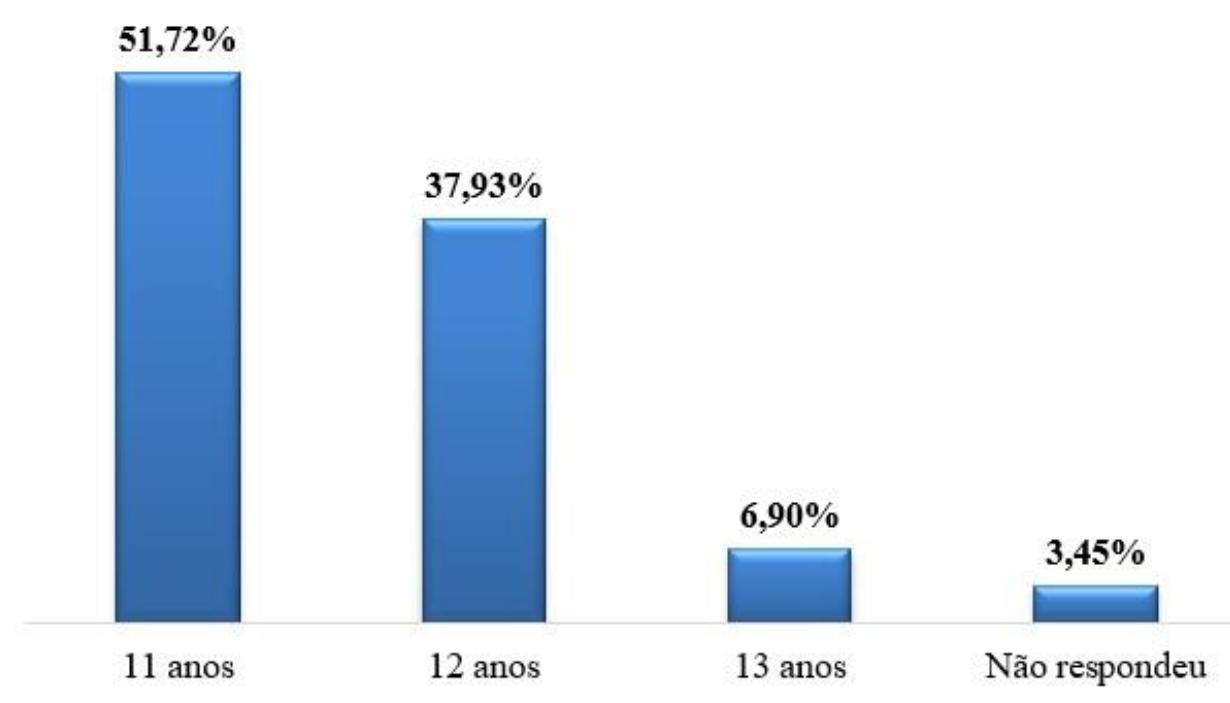

Figura 3: Idade dos alunos do 6ำ ano do ensino fundamental menor da Unidade Escolar Padre Elizeu Cavalcante. Fonte: Autoras (2019).

De acordo Silva e Wolf (2015) a criança inicia o sexto ano, mais ou menos aos 11 anos, momento que corresponde o início da adolescência (puberdade), que é a fase da vida que intermédia a infância e a idade adulta.

No que se refere ao local de habitação cerca de $86,20 \%$ residem na zona urbana e 13, 79\% na zona rural. Quando questionados sobre com quem moravam, verificou-se que aproximadamente $65,52 \%$ moram com pai e mãe, $13,79 \%$ com apenas mãe, $10,34 \%$ com os avós e 3,45\% com tio, pai e mãe ou avós.

Em relação à origem da renda dos responsáveis pôde-se constatar que cerca de $34,48 \%$ trabalham com outros tipos de atividade no qual não foram citadas pelos alunos, $27,59 \%$ são donas de casa, $17,24 \%$ possuem comércios, $10,34 \%$ realizam atividades na agricultura, $6,90 \%$ no serviço publico e agricultura e 3,45\% não soube responder, conforme mostra a Figura 4. 


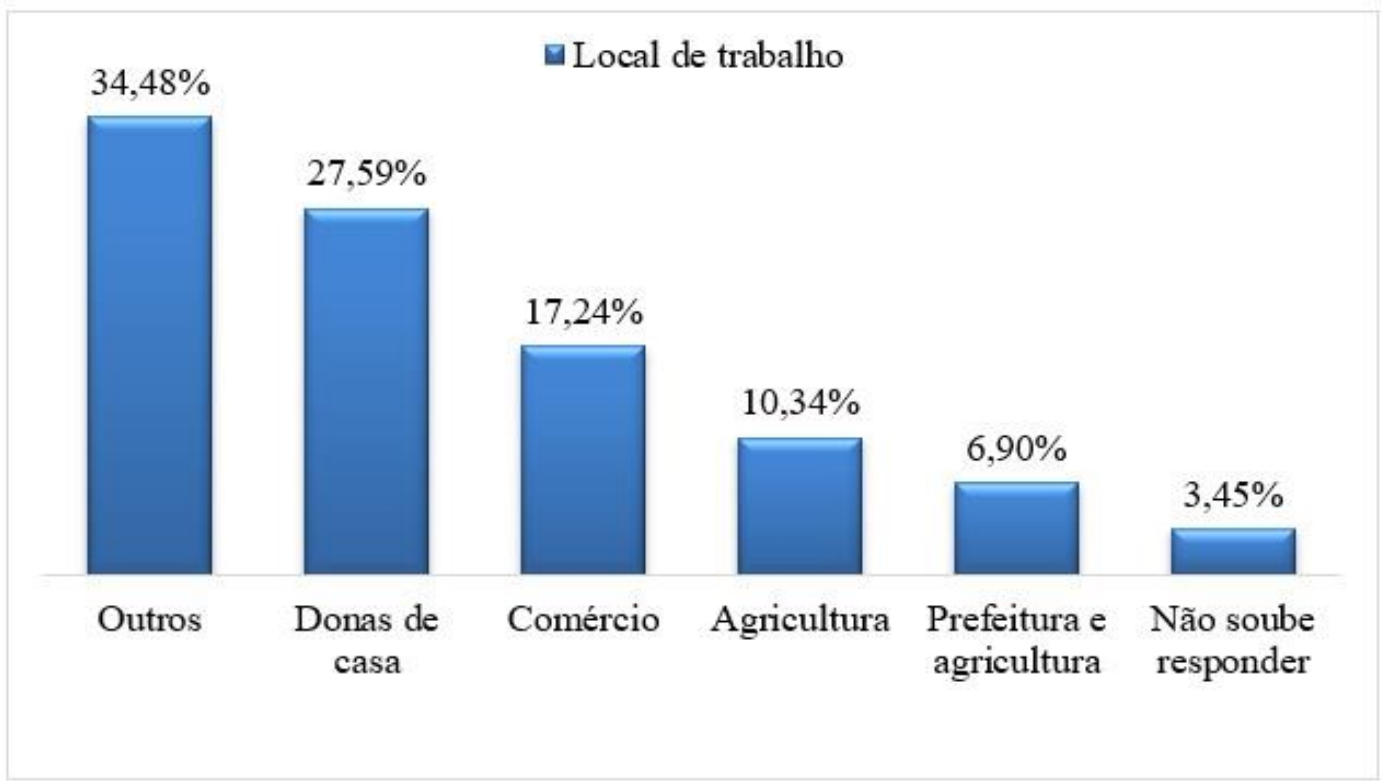

Figura 4: Ocupação dos responsáveis pelos alunos do 6ำ ano do ensino fundamental menor na Unidade Escolar Padre Elizeu Cavalcante. Fonte: Autoras (2019).

Ainda com relação às respostas autodeclaradas dos alunos sobre a atividade de obtenção de renda dos pais, faz-se necessário explanar que cerca de $34,48 \%$ dos alunos não souberam explicar a ocupação dos pais ou ainda não conseguem relacionar com as opções elencadas no questionário ou no contexto local.

Por fim, nessa etapa quando questionados se em suas residências é conversado com familiares sobre as questões ambientais, no intuito de incentivá-los a adotar boas práticas a fim de educá-los, constatou-se que 93,10\% responderam que sim e 6,90\% que não. Deste modo, já se tem um indicativo que o contexto da Educação Ambiental já era fomentado na casa dos alunos.

\section{Diagnóstico}

Posteriormente no questionário foi solicitado aos alunos que demonstrassem por meio de um desenho o seu entendimento sobre o que vem a ser meio ambiente. Com a tabulação dos dados observou-se que antes da exibição do filme $48,27 \%$ dos alunos consideraram o meio ambiente como sendo os seres bióticos, tendo como exemplo, as plantas e os animais, e abióticos como o solo, a água e o ar, já $41,38 \%$ representaram o meio ambiente com intervenção antrópica como o derramamento de petróleo e o desmatamento, e os outros $10,34 \%$ consideram o ser humano como parte integrante do meio ambiente. Já após a exibição do filme $41,38 \%$ dos alunos consideram o meio ambiente como sendo os seres bióticos e abióticos, 48,27\% responderam que o meio ambiente possui intervenções antrópicas e 10,34\% consideram o indivíduo como parte do meio ambiente, conforme mostra a Figura 5. 


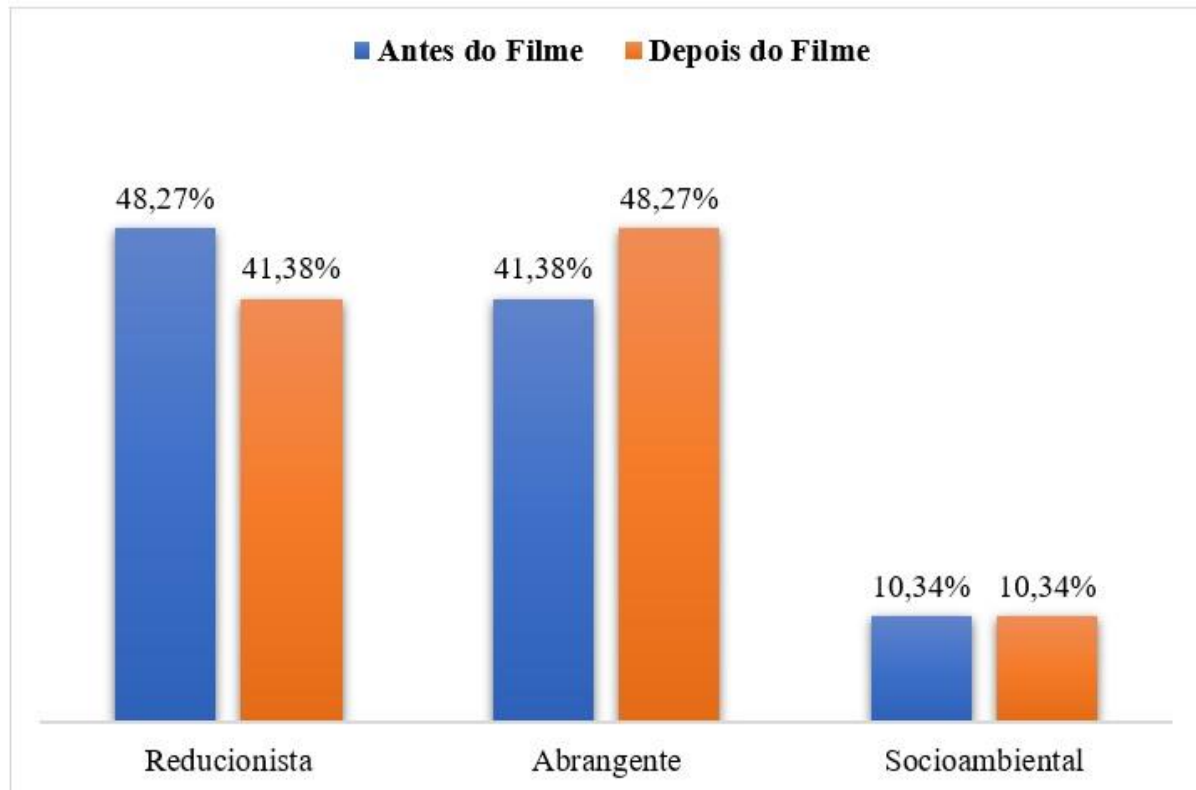

Figura 5:Percepção por meio de desenho da relação existente entre o homem e o meio ambiente. Fonte: Autoras (2019).

Ao analisar a Figura 5, observa-se que antes do filme os alunos tinham uma maior percepção sobre o meio ambiente como sendo o meio físico, tais como água e os animais, no entanto, após o filme essa percepção mudou houve um aumento da percepção dos alunos para ver o meio ambiente com intervenção humana.

Foi possível perceber alguns dos problemas que o meio ambiente sofre em decorrência da ação antrópica. Entretanto, os percentuais sobre meio físico ainda continuaram bastante altos, isso pode ser em decorrência de que a percepção do meio ambiente físico foi construída socialmente ao longo do tempo e já a com intervenção antrópica e o ser humano como parte do meio é uma visão que está ainda sendo desenvolvida.

Nas figuras abaixo é possível visualizar as percepções diferenciadas de meio ambiente como meio ambiente físico, meio ambiente com intervenção antrópica e o ser humano como parte do meio, conforme mostra as Figuras de 6 a 8 (próximas páginas).

Em relação ao meio ambiente com intervenção antrópica os alunos demonstraram através dos desenhos alguns problemas que são causados a natureza como a derrubada das árvores, o descarte de lixo (resíduos), poluição do ar por uma cerâmica. A Figura $7 f$ desenhada antes do filme mostra 0 derreamento de petróleo e lixo (resíduos) em poucas quantidades, e a Figura $7 \mathrm{~h}$ feita posteriormente ao filme demonstra um aumento da quantidade de resíduos nas representações dos desenhos, tendo em vista que, no filme é retratada a questão do consumo exagerado realizado pelo homem e a consequente geração de lixo (resíduo). 


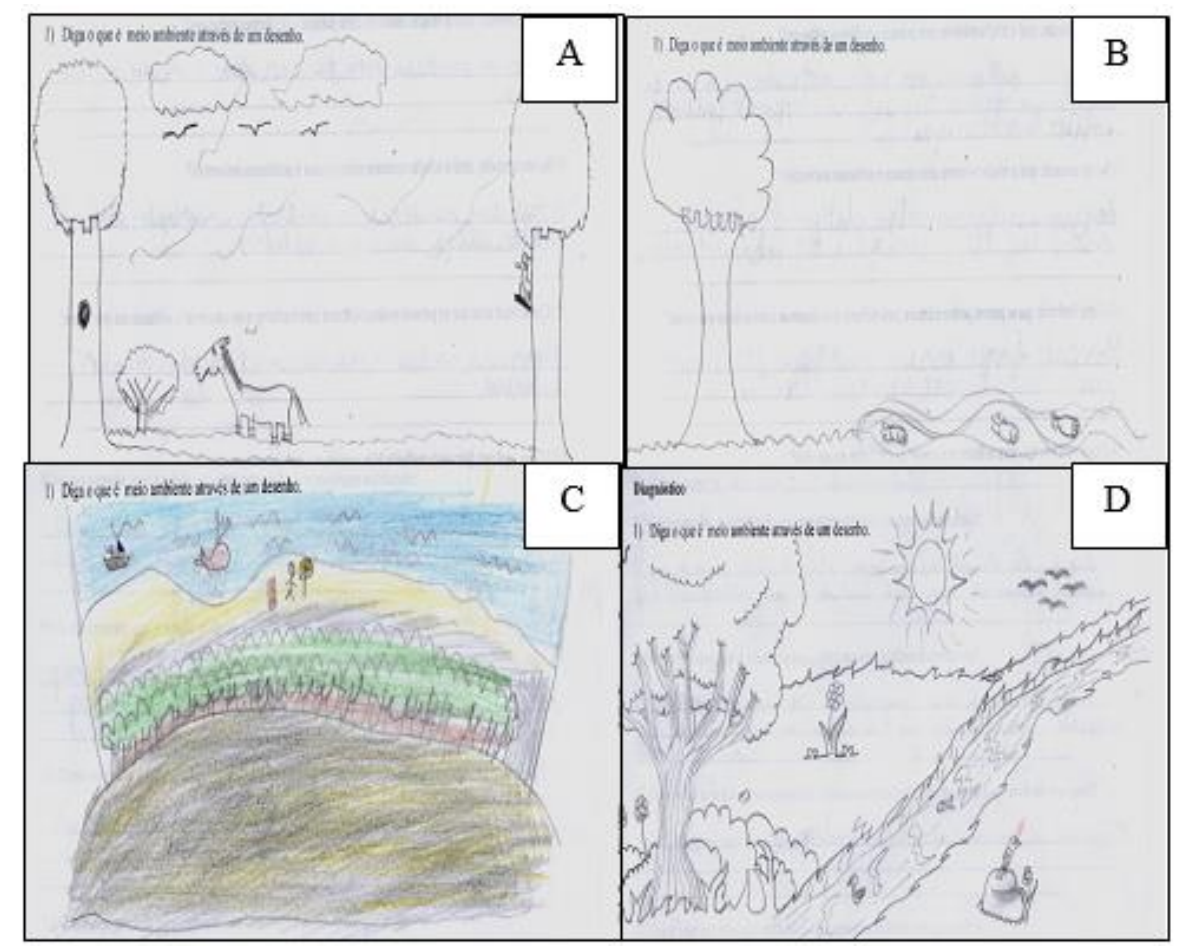

Figura 6: Desenho representando o meio ambiente como meio físico, por alunos do 6ํano da Unidade Escolar Padre Elizeu Cavalcante, antes e depois da exibição do filme, respectivamente. Fonte: Autoras (2019).

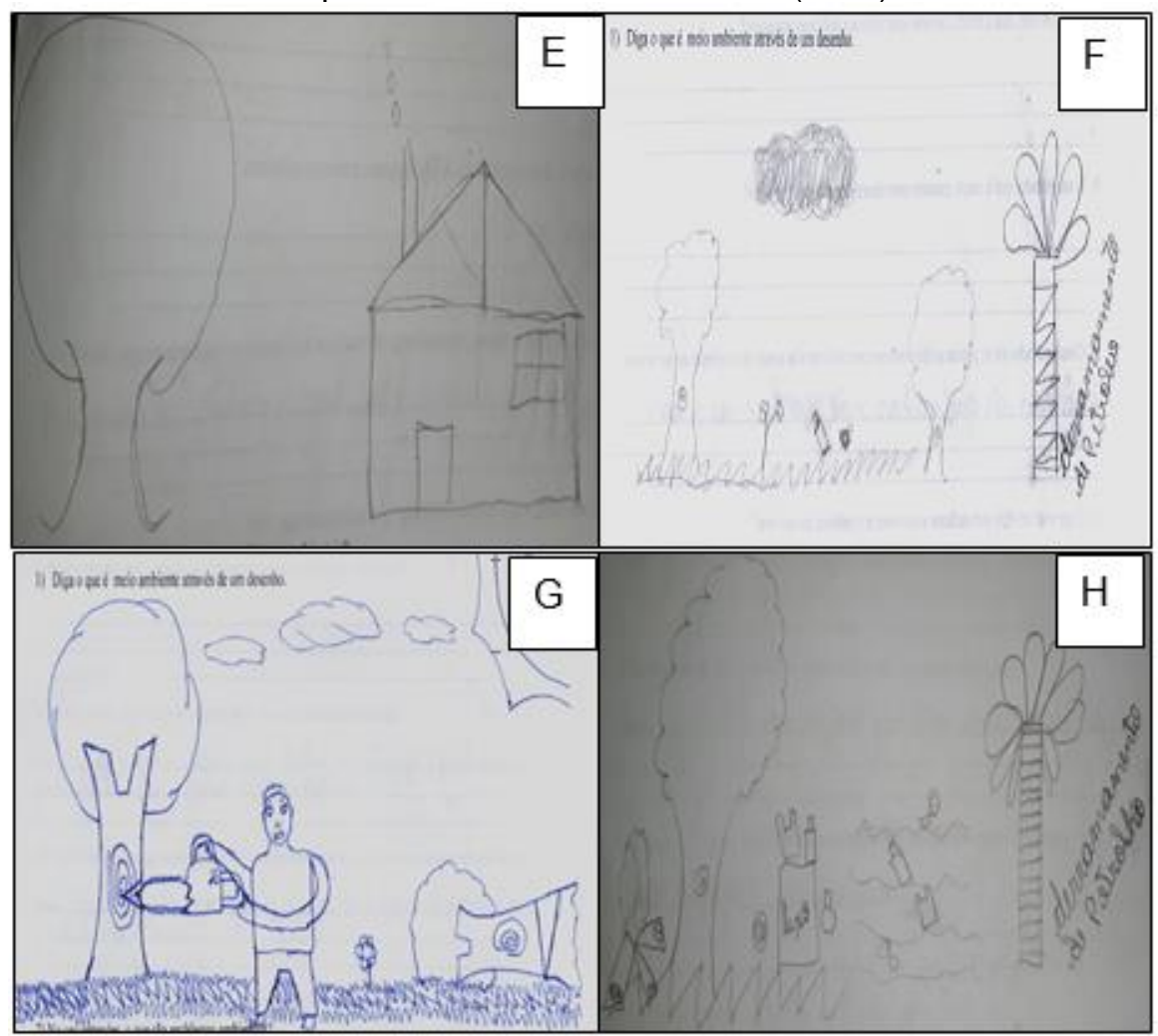

Figura 7: Desenho representando meio ambiente com intervenção humana, por alunos do 6은 ano da Unidade Escolar Padre Cavalcante, antes e depois da exibição do filme, respectivamente. Fonte: Autoras (2019). 
Com esses indicativos nos desenhos é possível visualizar que uso da metodologia de exibição de filmes relacionada à temática ambiental pode ser uma boa ação de intervenção no contexto escolar contribuindo para melhor compreensão e aprendizado e aprimorando o conhecimento dos alunos.

No que diz respeito ao ser humano como parte do meio os alunos desenharam uma casa dentro do planeta Terra, para representar a relação do meio ambiente com os seres humanos e ainda um casal em harmonia com a natureza tanto antes como depois do filme, como mostra a Figura 8.

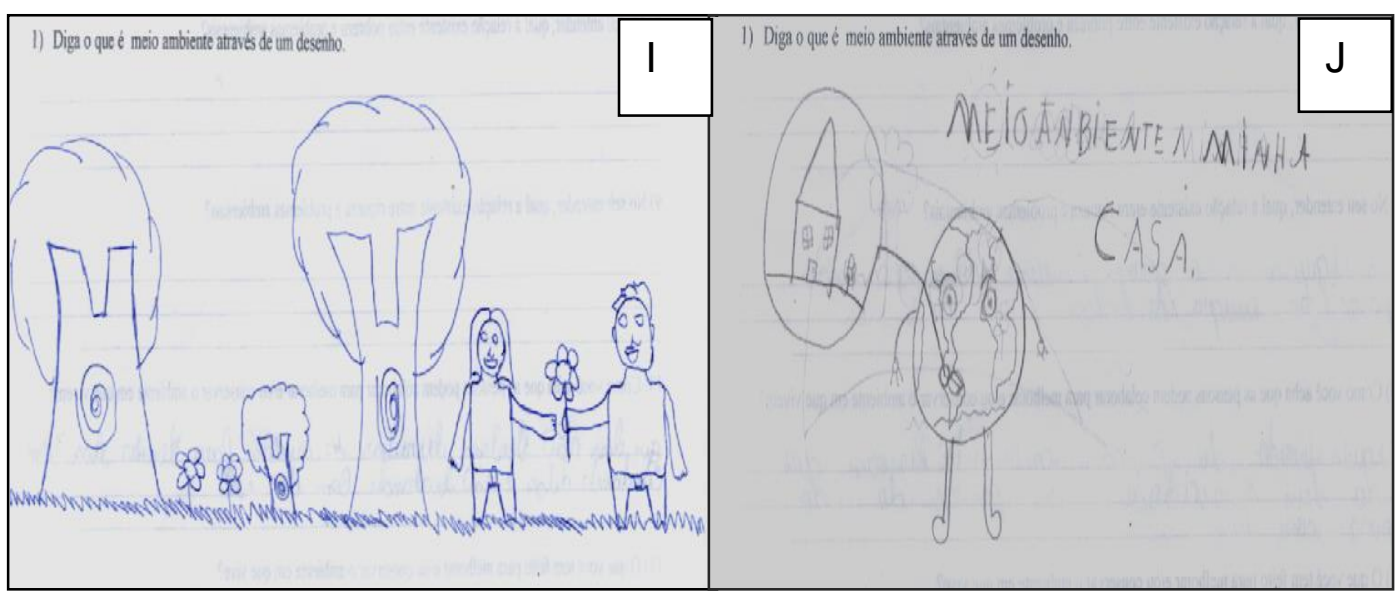

Figura 8: Desenho representando o ser humano como parte do meio ambiente, por aluno do 6은 ano da Unidade Escolar Padre Elizeu Cavalcante antes e depois da exibição do filme, respectivamente. Fonte: Autoras (2019).

De acordo Silva (2000), meio ambiente vem a ser a "interação do conjunto de elementos naturais, artificiais e culturais que propiciam o desenvolvimento equilibrado da vida em todas as suas formas". Migliari Junior (2001) conceitua meio ambiente como a "integração e a interação do conjunto de elementos naturais, artificiais, culturais e do trabalho que propiciem o desenvolvimento equilibrado de todas as formas, sem exceções. Logo, não haverá um ambiente sadio quando não se elevar, ao mais alto grau de excelência, a qualidade da integração e da interação desse conjunto".

Na verdade, não só em termos de utilização dos recursos, mas de ocupação de espaço, de agressão do meio ambiente e mesmo de ameaça a outras espécies (uma população em crescimento acelerado é suficiente para comprometer todos estes aspectos). É relevante lembrar, no entanto, que a ameaça do crescimento demográfico surge não apenas como valores numéricos por ele apresentado, mas, também, pelos atributos sociais que manifesta. No entanto, que a ameaça do crescimento demográfico surge não apenas como valores numéricos por ele apresentado, mas, também, pelos atributos sociais que manifesta (KRZYSCZAK, 2016). 
Para Krzysczar (2016), o meio ambiente com o passar dos anos tem passado por diversas mudanças, com impactos tanto para ele em si, quanto para a humanidade. Em que o meio ambiente ao passar por fortes agressões pode ocasionar sua "destruição completa". Apesar da forte relação do ser humano com o meio ambiente, não é de hoje que vem sofrendo essas grandes agressões em virtude da intervenção antrópicas.

$O$ autor ainda ressalta que:

É fato de que, hoje, a relação entre o homem e o ambiente está bem definida, o homem é parte integrante dele, e suas peculiaridades de animal racional o dotam de meios para submeter, em larga parcela, a natureza, que só na aparência lhe é externa, porém na verdade, Ihe é inerente (KRZYSCZAK, 2016).

Quando questionado sobre quais os possíveis problemas ambientais presente nos dias atuais cerca de aproximadamente $62,06 \%$ responderam que essa problemática é causada pelo ser humano por meio da prática de queimadas, desmatamentos, poluição dos rios entre outros, já 24,14\% responderam que é visto como algo que prejudica o meio ambiente, em que destacaram o maltrato aos animais e a extinção destes, poluição do ar, quantidade considerável de lixo nas ruas como garrafas pet, papel e plásticos, havendo ainda em virtude desses problemas o surgimento de doenças, e destacaram ainda com $3,45 \%$ a poluição do solo, 3,45\% falta saneamento e $6,90 \%$ não souberam responder, conforme a Figura 9.

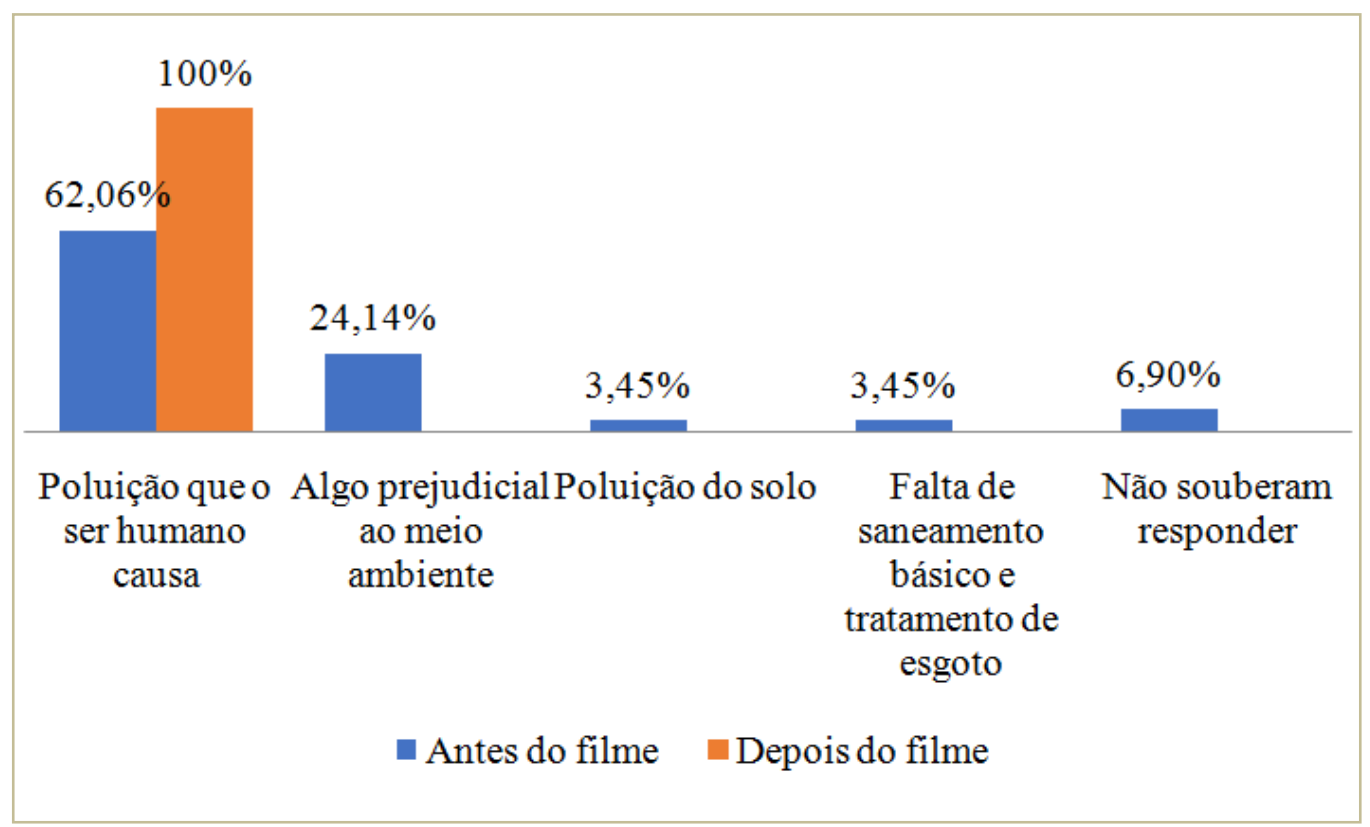

Figura 9: Percepção sobre os problemas ambientais. Fonte: Autoras (2019). 
Depois da exibição do filme verificou-se que $100 \%$ dos alunos responderam que os impactos causados no meio ambiente são ocasionados pela ação antrópica, destacando a questão de desmatamentos, queimadas, poluição do solo e tudo que de algum modo possa prejudicar o meio ambiente.

Para Borinelli (2011) os principais problemas ambientais e que servem de indicadores da crise ambiental são: a devastação das matas; contaminação da água; contaminação de costas e mares; sobre-exploração de mantos aquíferos; erosão dos solos; desertificação; perda da diversidade biológica; destruição da camada de ozônio e aquecimento global do planeta; superpopulação e a pobreza.

Em relação aos problemas ambientais presente na cidade tanto antes, quanto depois da exibição do filme, $100 \%$ dos alunos responderam que existem estes problemas, que destacaram o descarte de lixo nas ruas, desmatamento, poluição dos rios e do ar como sendo os principais. Quando questionado sobre os incômodos ocasionados por estes problemas $100 \%$ dos entrevistados relataram que se sentem incomodados, isso antes e após o filme, em decorrência dos problemas que ocasionam a poluição, modificando a paisagem urbana, prejudicando a saúde das pessoas e a morte dos animais.

Os problemas ambientais afetam tanto o meio ambiente quanto a qualidade de vida da sociedade. E atualmente um dos problemas mais preocupantes é a grande perda da biodiversidade que se dar em virtude de vários outros problemas sofrido pelo meio ambiente. E por muitas vezes, por serem irreversíveis, e estarem ocorrendo em grande escala, é extremamente importante que se busque soluções no intuito de minimizá-los (SILVA; REIS, 2009).

No que diz respeito aos responsáveis pelos problemas ambientais 93,10\% responderam que são causados pelos seres humanos, já 3,45\% responderam que são causados em decorrência da presença de lixo e 3,45\% não souberam responder. Quanto aos responsáveis pela solução destes problemas $93,10 \%$ destacaram que são os seres humanos, assim como, uma pequena parcela dos alunos, que disseram que tais problemas devem ser realizados por ambientalistas, e que os seres humanos devem preservar o que os pertencem e fazer o melhor para a coletividade, e 6,90\% não souberam responder.

No questionário aplicado após a exibição do filme, no que diz respeito aos responsáveis pelos problemas e soluções $100 \%$ dos alunos responderam que são causados pelo ser humano e destacaram os mesmos como responsáveis pela solução destes problemas os ambientalistas. No entanto, é importante que o professor esteja atento a essa mudança de percepção e que trabalhe na sala de aula os impactos ambientais naturais e os impactos ambientais positivos realizados pelos seres humanos.

Conforme mostra estes dois resultados relacionados aos responsáveis pelos problemas ambientais e soluções, percebe-se que antes do filme os alunos destacaram os seres humanos como responsáveis. Já após o filme às

revista brasileira educação ambiental 
respostas foram unânimes em que apontaram somente os seres humanos como os principais responsáveis pelos problemas ambientais e soluções.

Diante de tal cenário, é de grande importância que sejam adotadas práticas que visem minimizar os impactos causados pelo próprio ser humano, buscando inserir ações para que as pessoas possam exercer na sociedade (SEVERO et al., 2016).

A relação sobre pobreza e riqueza com os problemas ambientais também foi abordada e em se tratando da relação do meio ambiente com riqueza $62,06 \%$ não souberam responder, $34,48 \%$ relataram que as pessoas que possuem maior poder aquisitivo não se preocupam com a proteção do meio ambiente e $3,45 \%$ responderam que estes são os principais responsáveis pelo desmatamento. Com respeito à relação da pobreza e problemas ambientais, 58,61\% também não souberam responder, 41,38\% responderam que as pessoas com menos poder aquisitivo não possuem uma boa condição e nem conhecimento acerca dos problemas ou até mesmo de como proteger o meio e em virtude disto acabam ocasionando mais problemas ao meio ambiente, como mostra a Figura 10.

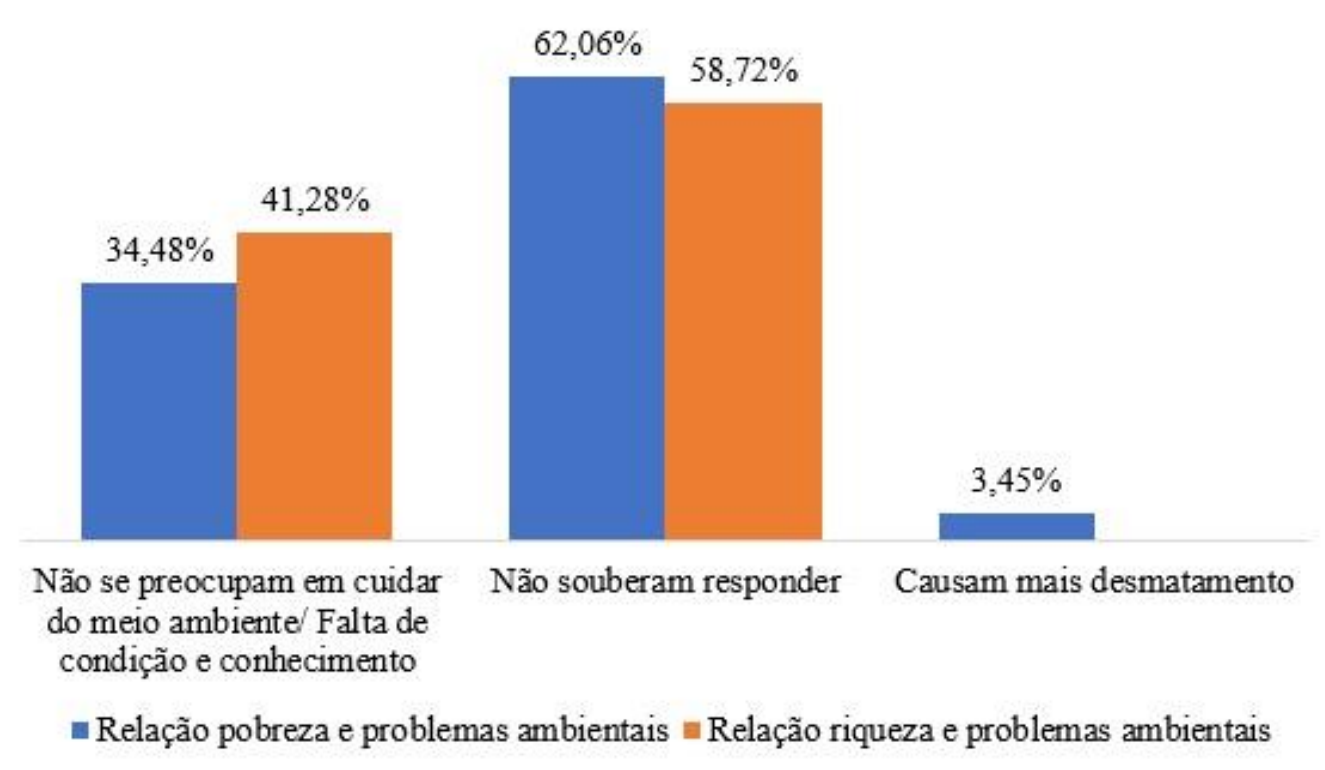

Figura 10: Relação existente entre riqueza e pobreza sobre o meio ambiente antes do filme, respectivamente. Fonte: Autoras (2019).

Com um percentual tão alto de alunos que não conseguem relacionar problemas sociais ao ambiental se vislumbra um indicativo de que a Educação Ambiental formal precisa ser aprimorada nas escolas a partir de abordagens interdisciplinares, inserindo o contexto social e a realidade local nas discussões.

$\mathrm{Na}$ relação existente entre riqueza e problemas ambientais, os alunos responderam após a exibição do filme $89,65 \%$ que as pessoas mais ricas Revbea, São Paulo, V. 14, № 4: 87-105, 2019. 
geram muito lixo nas residências, geralmente se importam mais em usufruir dos recursos naturais sem se preocupar em cuidar dos mesmos, não sofrem tanto com os problemas ambientais, pois possuem acesso ao saneamento básico e 10,34\% não souberam responder.

Já em relação à pobreza e problemas ambientais $93,10 \%$ dos alunos responderam que as pessoas mais pobres possuem mais dificuldade em obter informações sobre os problemas ambientais em que muitas dessas pessoas se encontram condições muitas vezes precárias pelo fato de morarem em áreas que não possuem saneamento básico, havendo dessa forma a exposição direta aos insetos causadores de doenças e 6,90\% não souberam responder, como mostra a Figura 11.

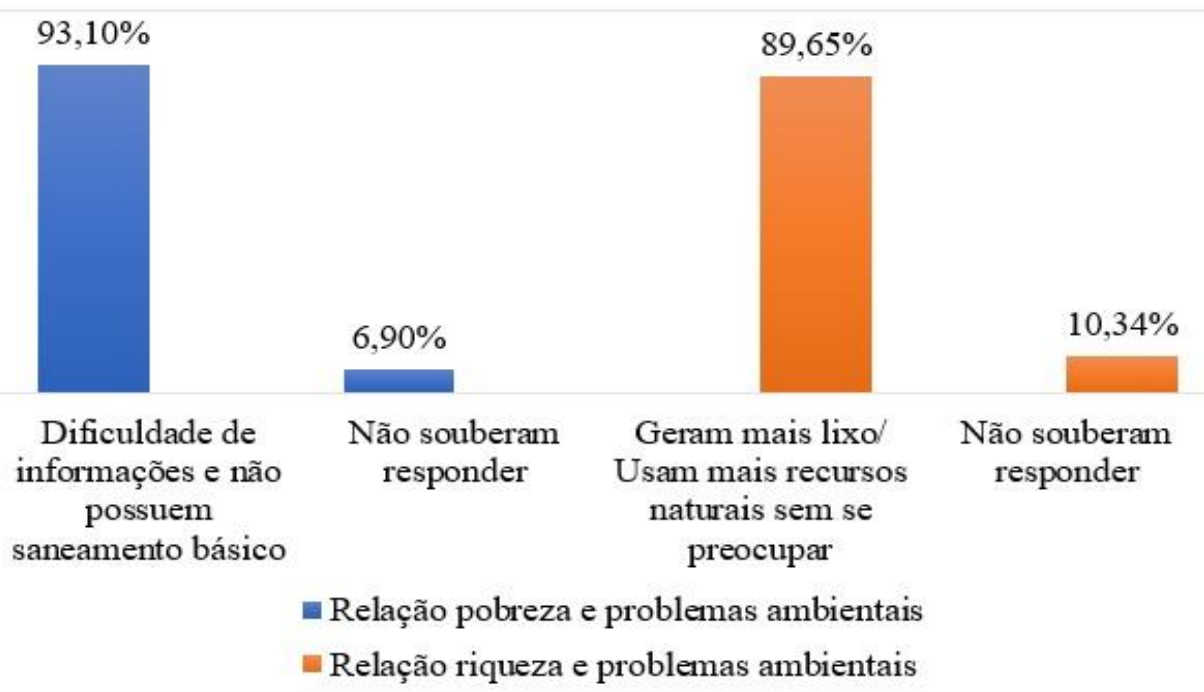

Figura 11: Relação existente entre riqueza e pobreza sobre o meio ambiente depois do filme, respectivamente. Fonte: Autoras (2019).

Ao analisar essas informações da relação pobreza, riqueza com os problemas ambientais observou-se que antes do filme a maioria dos alunos representando um total de $66,06 \%$ da relação com a riqueza e $58,61 \%$ com relação com a pobreza não souberam responder à questão, no entanto, após o filme $93,10 \%$ com relação à pobreza e $89,65 \%$ da relação com a riqueza conseguiram fazer a relação destas, com os problemas ambientais. Isso demonstra que a metodologia utilizada por meio do uso de filmes contribuiu de forma positiva para o entendimento dos alunos em relação à sociedade e o meio ambiente.

Quando questionado sobre o que as pessoas poderiam fazer para melhorar ou conservar o meio ambiente $89,65 \%$ elencaram antes do filme as seguintes soluções: não jogar lixo nas ruas, na água e no solo, diminuir o uso de automóveis optando por andar a pé, diminuir o desmatamento, já 6,90\% não souberam responder e 3,45\% relataram que umas das soluções é processo de reciclagem. Em relação às práticas adotadas pelas pessoas para melhorar a qualidade do meio ambiente $86,20 \%$ responderam após o filme que se deve 
buscar reduzir o desmatamento, reduzir o uso de transportes, cuidar do meio ambiente, $6,90 \%$ respondeu reciclagem, 3,45\% ser menos consumista e 3,45\% não souberam responder, conforme mostra a Figura 12.

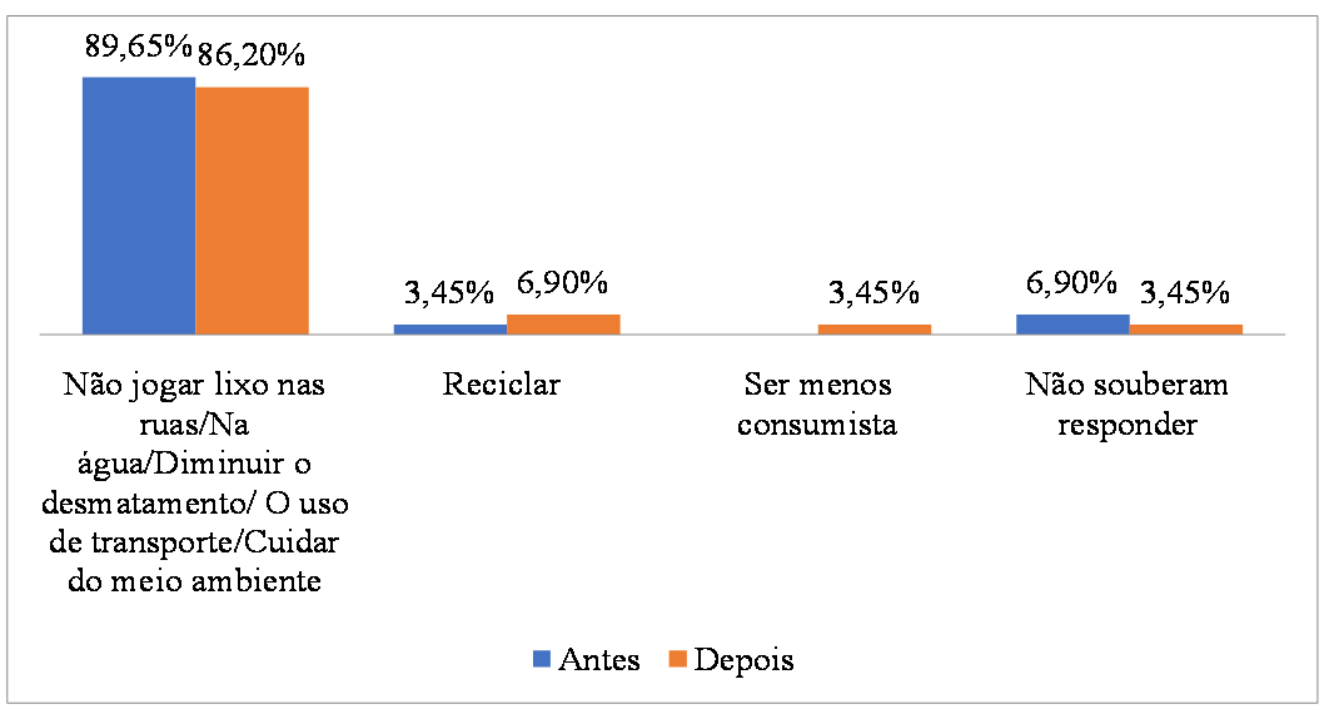

Figura 12: Métodos colaborativos na conservação do meio ambiente. Fonte: Autoras (2019).

Em relação ao que os alunos poderiam fazer para proteger o meio ambiente $93,10 \%$ responderam não jogar lixo nas ruas, não poluir o meio, proteger a flora, fazer a limpeza das vias públicas e não desmatar as florestas e cerca de 6,90\% não responderam. Quando questionado após o filme aos alunos sobre o que eles fazem para conservar o meio ambiente $96,55 \%$ responderam que devem reduzir o consumo de água fechando bem as torneiras, realizar o plantio de arvores, reciclar garrafas pet, não fazer queimadas, economizar energia, utilizar uma garrafa própria de água e 3,45\% não souberam responder, conforme a Figura 13.

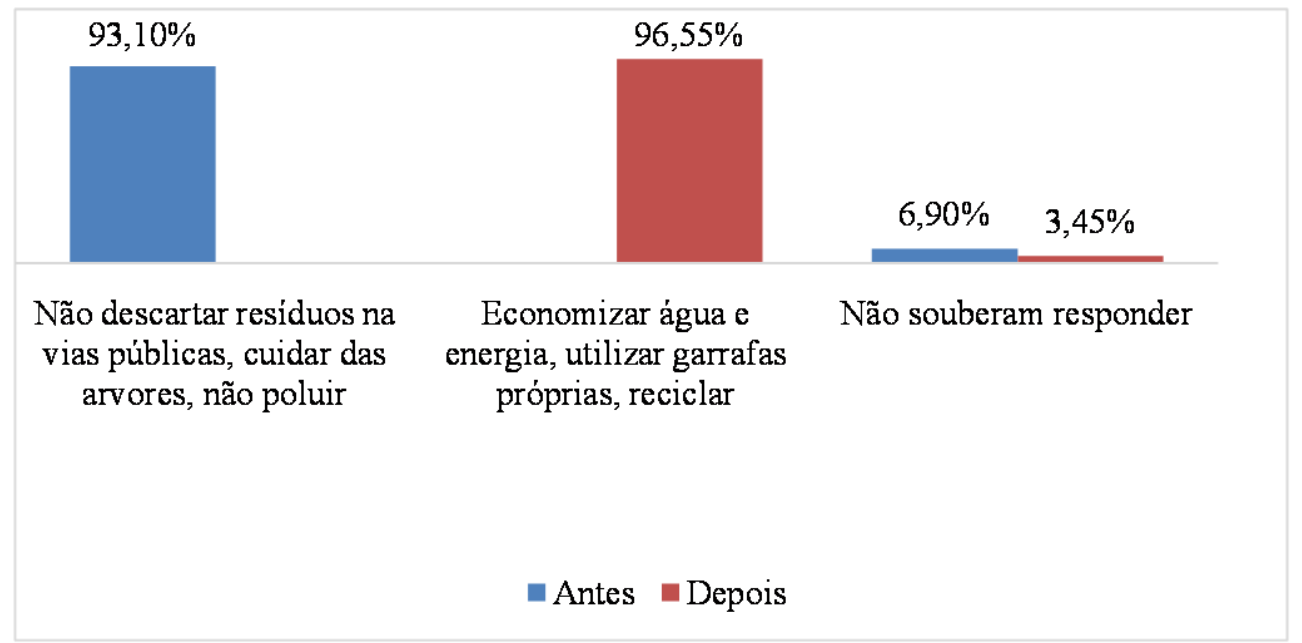

Figura 13: Práticas elencadas pelos alunos para promovem a conservação do meio ambiente antes e depois do filme. Fonte: Autoras (2019).

Revbea, São Paulo, V. 14, № 4: 87-105, 2019. 
Em virtude dos problemas ambientais, consequentemente tem-se gerado muitas preocupações para as pessoas, onde dessa maneira tem-se exigido cada vez mais, a inserção de práticas como, por exemplo, reduzir gastos excessivos de água e energia, fazer reflorestamento em áreas degradadas, reutilizar utensílios que possuem vida útil consideravelmente maior, entre outras, todas essas são práticas que visam reduzir e/ou eliminar os impactos gerados pelos mesmos, tudo isso em decorrência de suas próprias ações a respeito da problemática (NASCIMENTO COSTA, 2016).

No que diz respeito ao que eles aprendem em casa antes do filme $68,97 \%$ responderam que devem preservar o meio ambiente protegendo os animais e as plantas, evitar o desmatamento e $20,69 \%$ que não devem jogar lixo em locais inadequados e 10,34\% não souberam responder. Já após a exibição do filme $79,31 \%$ responderam que cuidam das plantas, buscam preservar o ambiente que vive e evitam o desmatamento, $17,24 \%$ responderam não jogar resíduos nas vias públicas e 3,45\%não respondeu.

Em relação aos resíduos sólidos presentes nas vias públicas antes do filme cerca de $93,10 \%$ relataram que possuem muitos destes resíduos nas vias públicas, como papel, garrafas, plásticos, latas pneus e aparelhos eletrônicos. Sendo que depois do filme $96,55 \%$ mencionaram os mesmos problemas, e antes do filme $6,90 \%$ não souberam responder, e depois $3,45 \%$ não respondeu.

Os dados mostraram alteração da percepção ambiental dos alunos após assistirem o filme, contudo, faz-se necessário acompanhamento contínuo das questões levantadas no mesmo e interligação com as disciplinas curriculares.

\section{Considerações finais}

A partir da análise científica realizada foi possível observar que os alunos consideram o meio ambiente a partir de visões diferenciadas sobre natureza e após concluído a elaboração dos desenhos, a seleção dos mesmos foi realizada dividindo em três categorias referente às concepções de natureza de acordo Malafaia e Lima Rodrigues (2009) sendo elas a reducionista (meio físico), abrangente (com intervenções antrópicas) e socioambiental (ser humano como parte do meio).

A visão socioambiental de natureza tanto antes quanto depois da exibição do filme foi representada pela minoria dos alunos, a mesma considera o ser humano como parte integrante do meio ambiente. Contudo, é necessário o destaque para essa visão, pois revela uma mudança de percepção ainda construção, uma visão relativamente recente nas sociedades contemporâneas.

Em relação aos problemas ambientais citados pelos alunos, verificou-se que a maioria dos alunos destacou como problemas o desmatamento, altos índices de queimadas, as questões da poluição dos rios em muitos moradores não possuem conhecimento sobre os problemas que isso podem gerar para a sociedade e, além disso, a poluição do solo e das ruas. No entanto, na hora de 
fazer a relação com a condição de pobreza e riqueza, ainda que a porcentagem relacional tenha aumentado significativamente após a exibição do filme, faz-se necessário trabalhar também a imagem positiva do ser humano no meio ambiente, o que reflete a necessidade de maior esclarecimento e estudo da relação meio ambiente e sociedade na escola.

Os resultados apresentados demonstram que a utilização de filmes como instrumento metodológico no ensino fundamental contribui para um melhor entendimento dos alunos sobre as questões ambientais e as atividades vivenciadas na sua realidade. Foi possível desenvolver a atenção para práticas adotadas para solucionar os problemas ambientais, os alunos relataram que seria de suma importância à redução do descarte de lixo nas ruas, na água e no solo, diminuir a utilização de automóveis, optando desse modo por andar a pé, reduzir os índices de desmatamento, fazer reciclagem e, além disso, cuidar do meio ambiente, relatados tanto antes quanto depois do filme.

Portanto, a experiência foi positiva com o uso do filme como instrumento metodológico de ensino e aprendizagem, o qual teve uma boa aceitação pelos alunos e se revelou um parâmetro para estudo da percepção ambiental no contexto escolar, bem como poderá contribuir para com os educadores na medida com possam utilizá-lo não só como animação lúdica, mas relacionando a capacidade de desenvolver múltiplas atitudes de conhecimentos e preservação do meio ambiente.

\section{Referências}

ASSOCIAÇÃO BRASILEIRA DE NORMAS TÉCNICAS (ABNT). ISO 14.001:2004. Sistema de gestão ambiental: requisitos com orientações para uso. Disponível em <http://www.abntcatalogo.com.br/norma. aspx?!D=1547>.

BRASIL. Lei Federal n. 6.938, 31 de agosto de 1981. Dispõe sobre a Política Nacional do Meio Ambiente, seus fins e mecanismos de formulação e aplicação.Disponível em: <http://www.planalto.gov.br/ccivil 03/leis/L6938.htm>

BRASIL Lei 9.795, de 27 de abril de 1999. Dispõe sobre a Educação Ambiental, institui a política nacional de Educação Ambiental e dá outras providências. Disponível em: <http://www.planalto.gov.br/ccivil 03/leis/ 19795.htm >. Acesso em: 21 fev. 2019.

BORINELLI, B. Problemas ambientais e os limites da política ambiental. Serv. Soc. Rev., Londrina, V. 13, N.2, P. 63-84, 2011.

FERREIRA, J. E; PEREIRA, S. G.; BORGES, D. C. S. A Importância da Educação Ambiental no Ensino Fundamental. Revista Brasileira de Educação e Cultura Centro de Ensino Superior de São Gotardo, 2013. Disponível em: $<$ http://periodicos.cesg.edu.br/index.php/educacaoecultura $>$. 
INSTITUTO BRASILEIRO DE GEOGRAFIA E ESTATÉTICAS (IBGE). Sinopse do Censo Demográfico: municípios do Piauí, 2019.

KRZYSCZAK, F. R. As diferentes concepções de meio ambiente e suas visões. Revista de Educação do IDEAU, v. 11, n. 23, p. 1-17, 2016.

MALAFAIA, G.; DE LIMA RODRIGUES, A. S. Percepção ambiental de jovens e adultos de uma escola municipal de ensino fundamental. Revista Brasileira de Biociências, v. 7, n. 3, 2009.

MIGLIARI JUNIOR, A. Crimes Ambientais. São Paulo: Lex Editora, 2001.

PORTO, R. G. C. O uso das mídias na Educação Ambiental. 2015.

SANTOS, G. A. S. S. O cinema como recurso didático no ensino da evolução das espécies e Educação Ambiental. Ideias e Inovação-Lato Sensu, v. 3, n. 1, p. 45-56, 2016.

SEVERO, E. A. et al. Análise da sustentabilidade ambiental, responsabilidade social e inovação de produto: um estudo empírico em empresas do Sul e Norte do Brasil. Revista ESPACIOS| Vol. 37 (№ 01) Ano 2016, 2016.

SOUSA, C. A. F. et al. A percepção ambiental de atores sociais de escolas públicas e privadas, em um bairro de João Pessoa (PB). Revista Brasileira de Educação Ambiental, v. 12, n. 4, p. 180-191, 2017.

SILVA, J. A. Curso de direito ambiental constitucional. 3 ed. São Paulo: Malheiros, 2000.

SILVA, S. S.; REIS, R. P. Problemas ambientais e o papel do Estado: que tipo de intervenção é necessária. Anais do $47^{\circ}$ Congresso SOBER-Sociedade brasileira de economia, administração e sociologia rural. Porto Alegre. 2009.

XAVIER, C. L.; NISHIJIMA, T. Percepção ambiental junto aos moradores do entorno do arroio Tabuão no bairro Esperança em Panambi/RS. Revista Eletrônica em Gestão, Educação e Tecnologia Ambiental. Santa Maria, v. 1, n. 1, p. 47-58, 2010. 